\title{
PARATEXTOS EM LIVROS LITERÁRIOS INFANTIS: Entre texto, paratextos e leitor
}

Flávia Brocchetto Ramos

Maria Isabel Silveira Furtado

Carla Beatris Valentin

Resumo: No processo de formação de leitores, os paratextos tendem a não ser considerados pelos mediadores. Diante disso, este artigo objetivou analisar como os paratextos podem incidir na leitura e recepção de uma obra. Toma-se como referência A bruxinha e o dragão, de Jean-Claude R. Alphen, obra que é analisada sob a perspectiva de paratextos (GENETTE, 2009) e sob o viés da leitura literária na escola (RAMOS, 2010, 2013). A análise desse livro deve-se a escolha feita por estudantes, integrantes de dois grupos focais, oriundos do quarto ano do Ensino Fundamental, entre títulos que compõem acervo do PNBE - 2014. O estudo indica que os elementos verbais e icônicos que constituem os paratextos complementam-se na apresentação da obra. Nessa perspectiva, a investigação sinaliza que, nos livros literários infantis, tais elementos podem ser um elo entre o leitor e o texto, para além dos fins de comercialização.

Palavras-chave: Paratextos. Leitura. Literatura Infantil. Escola.

\section{PARATEXTS IN CHILDREN'S LITERARY BOOKS: BETWEEN TEXT, PARATEXTS AND READER}

\begin{abstract}
In the process of training readers, paratexts tend not to be considered by mediators. Therefore, this article aimed at analyzing how paratexts can affect reading and reception of a literary work. The reference to A bruxinha e o dragão, by Jean-Claude R. Alphen, is analyzed from the perspective of paratexts (GENETTE, 2009) and from the perspective of literary reading at school (RAMOS, 2010, 2013). The analysis of this book is due to the choice made by students, members of two focus groups, from the fourth year of elementary school, among titles that make up the PNBE - 2014 collection. The study indicates that the verbal and iconic elements that constitute the paratexts complement each other in the presentation of the work. In this perspective, the investigation signals that, in children's literary books, such elements can be a link between the reader and the text, that goes beyond the purposes of commercialization.
\end{abstract}

Keywords: Parate+xts. Reading. Children's literature. School. 


\section{INTRODUÇÃO}

O presente estudo analisa os paratextos na obra $A$ bruxinha e o dragão, de Jean-Claude R. Alphen, que integra o acervo do Programa Nacional Biblioteca da Escola (PNBE) - 2014. A análise se sustenta, predominantemente, em referencial teórico baseado em Genette (2009), que conceitua paratexto editorial como "[...] aquilo por meio de que um texto se torna livro se propõe como tal a seus leitores" (GENETTE, 2009, p. 36). O estudo volta-se às produções verbais, ou não, como capa, título, nome do autor, ilustrador, selo, entre outras, que formam o conjunto de paratextos para a recepção do objeto livro.

A investigação empírica ocorreu em escola municipal, situada na Serra Gaúcha. Estudantes matriculados no $4^{\circ}$ ano do Ensino Fundamental foram os interlocutores empíricos que interagiram com obras selecionadas pelo PNBE 2014, acervo 3 do Ensino Fundamental. Os dados foram construídos por meio da realização de dois grupos focais, cada grupo é formado por seis estudantes que participaram de duas sessões planejadas e coordenadas pela pesquisadora, com vistas à interação com obras alocadas na biblioteca escolar, pertencentes ao referido acervo. Cada encontro teve a duração aproximada de uma hora. A pesquisa foi constituída e ancorada pelos cuidados éticos previstos nas resoluções $n^{\circ}$ 466/2012 e no 510/2016, do Conselho Nacional de Saúde (CNS) e referendado pelo Comitê de Ética e Pesquisa da Universidade de Caxias do Sul (CEP-UCS) pelo Parecer Consubstanciado CAAE: 01601418.2.0000.5341.

Este artigo inicia-se com breve discussão acerca dos critérios de seleção de livros literários destinados às escolas pelo PNBE 2014. Em seguida, são descritos os elementos paratextuais inerentes aos títulos, aqueles que identificam o Programa e ainda os que estão associados a alocação das obras no acervo escolar, como também nos propomos a pensar sobre os efeitos desses elementos na mediação do objeto livro. O artigo ainda atenta para a posição das crianças frente ao exemplar em questão.

\section{OBRAS LITERÁRIAS INFANTIS DESTINADAS À FORMAÇÃO DE LEITORES NA ESCOLA}

$\begin{array}{ccrrr} & \text { Programas } & \text { de } & & \text { distribuição } \\ \text { de } & \text { livros, } & \text { como } & \text { o } & \text { PNBE }\end{array}$

, facilitavam o acesso às obras literárias, o que, seria "[...] uma estratégia que possibilitaria ao estudante de toda escola pública, independentemente da sua condição social e cultural [...]” (RAMOS, 2013, p. 143), ler e conhecer literatura.

O objetivo do PNBE era democratizar o acesso aos bens culturais. O Programa visava à distribuição de obras literárias que pudessem contribuir para a formação de leitores, oportunizando aos estudantes a interação com a cultura letrada. Nessa direção, "[...] a literatura destinada à criança surge como um recurso que auxilia na educação dos pequenos, atuando como um reforço à família e à escola na formação do homem" (RAMOS, 2013, p. 13). Assim, a educação literária potencializa a interação da criança com bens culturais da sociedade, ultrapassando os muros da escola e ampliando as experiências do humano por meio dos livros.

O acervo do PNBE 2014 contemplava quatro categorias: Categoria 1 - Educação Infantil que atendia creche; Categoria 2 - Educação Infantil Pré-escola; Categoria 3 - Anos Iniciais do Ensino Fundamental; Categoria 4 - Educação de Jovens e Adultos (EJA). As obras analisadas, neste estudo, pertencem à categoria 3 - Anos Iniciais -, formada por 100 obras literárias infantis, divididas em 4 acervos de 25 títulos cada. O Edital de convocação 04/2012 - CGPLI delimitava os critérios para 
inscrição e seleção dos títulos e indica os gêneros selecionados:

3.2.3.1. Textos em verso - poema, quadra, parlenda, cantiga, trava-língua, adivinha; 3.2.3.2. Textos em prosa - pequenas histórias, novela, conto, crônica, teatro, clássicos da literatura infantil;

3.2.3.3. Livros de imagens e livros de histórias em quadrinhos, dentre os quais se incluem obras clássicas da literatura universal, artisticamente adaptadas ao público dos anos iniciais do Ensino Fundamental; [...] (BRASIL, 2012, p. 2).

O documento também aponta a busca pela qualidade das obras enviadas para as escolas brasileiras, além da diversidade de gêneros textuais dos títulos escolhidos, o que propiciaria ao leitor acesso ao mundo letrado da literatura de modo prazeroso e artístico. A avaliação das obras selecionadas era realizada por Instituições de Ensino Superior embasadas nos critérios previstos no Edital.

$\mathrm{Na}$ escolha de obras para o público infantil, "[...] é fundamental observar a presença de um caráter artístico, a fim de contribuir para a formação de um repertório que ultrapasse a literatura de massa". (RAMOS, 2013, p. 13-14). A tentativa de proporcionar obras artísticas nos ambientes escolares teve grande relevância na formação de leitores, para além da leitura didática. Nos diversos editais do Programa, sempre havia critérios literários para a seleção dos acervos, em virtude da natureza do objeto a ser indicado. As obras literárias infantis devem contemplar elementos, como "possibilidades de fruição estética e a ampliação do vocabulário dos leitores, de acordo com sua faixa etária e nível de letramento, ao lado da multiplicidade de gêneros e da consistência e coerência textual e discursiva das obras." (MOTA, 2012, p. 309).

Além de observar a coerência textual e discursiva do miolo do livro, é pertinente considerar a composição da obra, inclusive, os paratextos, afinal, esses elementos serão o elo entre o possível leitor e o objeto livro no momento da seleção e na leitura da obra, que muitas vezes ocorre sem a mediação de um leitor maduro. Para tanto, a proposta editorial do livro, o miolo e a ação do leitor farão parte de relações determinantes para compreender o título.

O processo de avaliação das obras selecionadas pelo PNBE 2014, guiado pelo Edital 04/2012 - CGPLI, aponta critérios de seleção no Anexo 2, acerca de elementos paratextuais:

O projeto gráfico será avaliado quanto à adequação e expressividade nos seguintes aspectos: apresentação de capa criativa e atraente, apropriada ao projeto estético-literário da obra; uso de tipos gráficos, espaçamento e distribuição espacial adequados aos diferentes públicos de leitores; uso de papel adequado à leitura e ao manuseio pelos diversos públicos e pertinência das informações complementares. A presença de erros de revisão e/ou de impressão comprometerá a avaliação da obra. [...]A biografia do(s) autor(es) deverá ser apresentada de forma a enriquecer o projeto gráfico e promover a contextualização do autor e da obra no universo literário. (BRASIL, 2012, p. 2-3).

O Edital 04/2012 do Fundo Nacional da Educação (FNDE) alerta para a obrigatoriedade de alguns elementos paratextuais, o que remete à relevância dos paratextos na recepção dos livros. A seleção das obras pelo Edital requereu cuidados especiais quanto à capa, no projeto de editoração, por ser, em geral, a parte do exemplara que gera o primeiro contato do possível leitor com o livro. Entretanto, pode haver exagero na apresentação da obra, com elementos incoerentes com o texto na

[...] tentativa de atrair o leitor, o projeto gráfico termina emprestando excessiva modernidade à capa, contrariando o interior do livro. $\mathrm{O}$ inverso também acontece, ou seja, livros com capas excessivamente sóbrias, sem nenhum convite à curiosidade do leitor, apesar de trazerem histórias para lá de divertidas. (MOTA, 2012, p. 310).

A capa como o primeiro elemento de contato com o leitor traz informações relevantes 
quanto à compreensão do título. Os elementos que a compõem podem ser um dos motivos pelos quais possa existir aproximação ou rejeição do leitor com a obra, essa interação emerge ao refletir sobre as condições ofertadas para a formação de leitores na infância dentro da escola.

Obras inscritas para compor o acervo do PNBE 2014 foram avaliadas conforme critérios postos no Edital, o que atesta qualidade do material. Muitas vezes, no entanto, as escolas não observam critérios artísticos na aquisição de livros escola, pois o critério

[...] dos estabelecimentos de ensino para a compra de livros, quando há verba, é, geralmente, o preço do exemplar, em virtude da preocupação com a quantidade, ou seja, com a ampliação do número de exemplares. $\mathrm{E}$ o livro literário para criança tem preço elevado, devido a aspectos como o tipo de papel utilizado, a presença de cores variadas no projeto editorial, a gramatura do papel, entre outros. (RAMOS; NEVES 2009, p. 48).

Entretanto, a disponibilidade das obras às instituições não garante a interação dos estudantes com os livros literários. A educação literária contempla olhar sensível dos professores e dos gestores às especificidades do processo de formação de leitores, com mediação de leitura literária que familiarize o estudante com as obras.

A obra analisada neste artigo pertence ao acervo do PNBE 2014 e foi selecionada por estudantes integrantes da pesquisa. É um texto híbrido que combinam o verbal e o visual e, de acordo com Nikolajeva e Scott (2011, p. 13), “[...]; pode-se dizer que os livros ilustrados comunicam por meio de dois conjuntos distintos de signos, icônico e convencional". Os signos convencionais complexos compõem a escrita, decifrada pelos falantes da língua empregada no discurso, já os signos icônicos representam o significado mais direto, por exemplo, as imagens. Essa junção constrói inúmeras possibilidades de compreensão da obra lida, e esse processo favorece a leitura literária infantil como um ato de autonomia e criticidade.

Gostos e preferências, segundo Ramos (2013, p. 14), têm relação direta com aprendizagens, de modo que a leitura literária é ensinada e aprendida. Os livros literários alocados na biblioteca escolar carecem de mediação para que o leitor em formação interaja com as especificidades do universo simbólico da literatura.

\section{PARATEXTOS NOS LIVROS LITERÁRIOS}

O que o leitor encontra no livro literário? Uma resposta inicial diria que é o texto. Mas no livro, há outros elementos que o compõem como a capa, o título, a sinopse, o nome da coleção, o nome do(a) autor(a) entre outros elementos que compõem um conjunto denominado como paratextos editoriais (GENET'TE, 2009, p. 36). O agrupamento desses elementos integra o objeto livro e, segundo o autor, dão ao livro a forma como se conhece hoje, ou seja, o paratexto "[...] constitui entre o texto e o extratexto uma zona não apenas de transcrição, mas também de transação" (GENETTE, 2009, p. 10). Nesse sentido, os discursos presentes nos paratextos ultrapassam as meras informações sobre o texto, eles integram a leitura, como elementos influenciadores na recepção da obra, na sua compreensão e no modo como apresentam o contexto em que o livro foi produzido e disponibilizado.

\section{A leitura dos paratextos pode ser} instrumento para investigar e criar possibilidades sobre o significado presente no miolo da obra. Tais sentidos gerados pelo paratextos incidem sobre o entendimento da obra pelos leitores e mediadores, sendo aspecto a ser considerado em títulos disponibilizados por uma política governamental, como é o caso da obra analisada neste estudo. Os livros integrantes do PNBE 
2014 estão acompanhados de paratextos editoriais padrão e de outros que identificam o Programa ao qual pertencem.

Na capa, localizam-se dois selos, um que exibe imagem do Programa, Ministério da Educação, com as siglas do FNDE e PNBE 2014, com a indicação de $1^{\circ}$ ao $5^{\circ}$ ano Ensino Fundamental, e outro com a escrita de "Venda proibida". Ambos apontam a origem dos livros que estão na escola e também fornecem orientações quanto à manutenção dos exemplares na biblioteca, para que a comunidade escolar os leia, proibindo a comercialização do material. Esses elementos paratextuais poderão inibir o uso das obras em outros locais que não sejam o espaço escolar. Os paratextos, nesse contexto, contemplam dados que vão além do texto e orientam acerca da localização e também da faixa etária a que obra se destina.

Na segunda capa, há uma nota destinada aos professores e estudantes que recebem os títulos:

Professores e Estudantes!
Esta obra faz parte do acervo distribuído às
escolas públicas pelo Ministério da Educação
no âmbito do Programa Nacional Biblioteca
da Escola - PNBE.
Os livros contribuem para garantir o acesso à
cultura e à informação. Eles podem ficar na
biblioteca para uso de estudantes e professores
e da comunidade escolar.
É de responsabilidade de todos cuidar bem
deste livro para que dure bastante e várias
pessoas possam aproveitar o material.
Boa leitura!

(BRASIL, Obras do PNBE, 2014, p. 1).

O texto aponta acerca da contribuição do livro perante o conhecimento da cultura e do lugar onde ficará alocado, a biblioteca. Orienta ainda, quanto aos cuidados que se deve ter com o exemplar, por fim, à disponibilidade a outras pessoas para que possam acessá-lo.

A nota dirige-se não só aos estudantes, mas também aos professores. Existe uma tentativa de comunicação com alunos e professores por parte do Programa, o que possibilita inferir relações sobre o uso da literatura como um direito de todos (CANDIDO, 1995). O paratexto do Programa indica que a obra está disponível para a comunidade escolar como um bem cultural.

O livro utilizado nesta investigação está registrado como pertencente ao acervo da biblioteca da escola onde aconteceu a empiria da pesquisa. Os exemplares recebem carimbo com os seguintes dados: nome da escola, da biblioteca, número e data de registro, na segunda capa. O acesso ao material pelo leitor está marcado na terceira capa, com o registro da obra na escola, nome do autor, título do livro, data de devolução, assinatura do(a) leitor(a) e a indicação da turma. Esse paratexto versa sobre as relações do objeto livro para com os leitores, indicando quem leu e quando leu. Essa ficha de registro evidencia o percurso do exemplar na escola, contudo cabe lembrar que a retirada não garante a leitura da obra.

\section{A BRUXINHA E O DRAGÃO: A PRESENÇA DE “FRANJAS" NO TEXTO}

A obra $A$ bruxinha e o dragão, de Jean-Claude R. Alphen, lançada no Brasilem 2013, pela editora Pearson Education do Brasil, aborda as fases da vida, da criança e do pai (um dragão), companheiro da filha. A bruxinha vivia em tempos distantes do leitor, era "cheia de personalidade" e podia escolher um dragão para lhe acompanhar: ela queria o maior, o mais veloz e valente. Vários candidatos apareceram, mas escolheu aquele que tinha asinhas de libélula, da família das lagartixas. A protagonista ao escolher um dragão com formas não esperadas, rompe com o estereótipo de beleza. Ao discorrer sobre o enredo deste livro, Joãozinho pertencente ao Grupo 2, um dos nossos interlocutores empíricos, sintetiza a história:

[...] é sobre uma bruxinha que quer fazer um dragão feroz. Seu pai se transforma em dragão. 
O dragão fica próximo a ela e é pequenininho e vai crescendo, chega um momento em que ela voa sozinha e ele deixa ela ir. E daí, o dragão foi crescendo e crescendo e ficando bem maior. (JOÃOZINHO, Grupo 2).

A obra convida os leitores a refletirem sobre as fases do crescimento e as suas necessidades, bem como a conduta do pai que para tentar proteger a filha, transformar-se em dragão, deixando implícito o cuidado paternal. $\mathrm{O}$ enredo rompe com ideias rotuladas de bruxa má, com a passagem da infância para a fase adulta, aproximando o horizonte de expectativas do leitor infantil com a personagem da obra. Aliás, “[...] para haver leitura, é fundamental que haja pontos de coincidência entre o horizonte do leitor e o texto." (RAMOS, 2010, p. 25). Também, a obra busca aproximar-se dos leitores, em virtude do universo infantil construído pelo enredo, ao retratar ações do pai para satisfazer as vontades da filha.

O enredo torna-se livro por meio dos paratextos, as franjas do texto (GENETTE, 2009), os quais são apresentados e analisados a seguir. Inicia-se pela capa, por se entender que é o primeiro elemento de aproximação entre o leitor e o livro.

No canto esquerdo da capa (Fig. 1), vê-se a Bruxinha na fase adulta, na sacada da torre de um castelo, vestida com roupa escura, cabelos louros compridos e com chapéu de bruxa a olhar o dragão. Este ocupa a maior parte da cena, é colorido, possui material pontiagudo na ponta da boca (como chifres), dentes pequenos, olhos saltados para cima da cabeça, em fundo preto com nuances azul escuro, dando indícios de noite estrelada. No lado direito superior da capa, localizam-se o nome do autor em tons de cinza; logo abaixo, o título da obra, em caixa baixa.
Figura 1 - Capa da obra: A bruxinha e o dragão

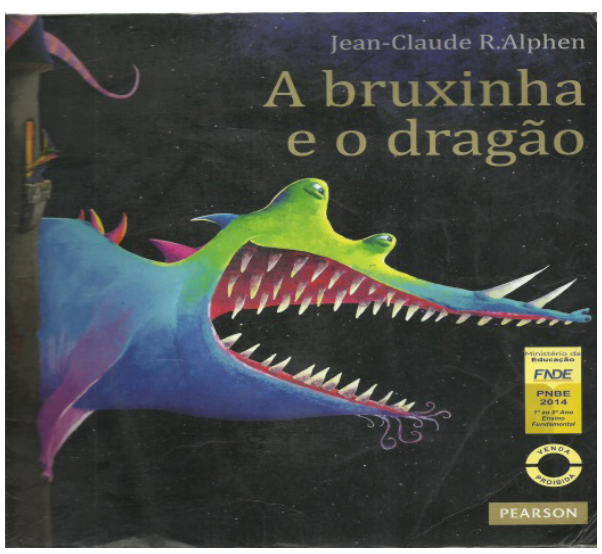

Fonte: Alphen (2013).

Os personagens não têm nome próprio, mas comparece no título a espécie a que pertencem, fato que pode convidar o leitor a conhecê-los. Além do título, a ilustração reitera as suas identidades, pois as ilustrações de ambos e os universos que os representam são mostrados visualmente. Nesse sentido, “[...] os títulos de livros ilustrados são parte muito importante da interação texto-imagem e contribuem para todos os tipos de interação que se observa dentro dos próprios livros" (NIKOLAJEVA; SCOTT, 2011, p. 312). Nesta obra, os protagonistas são anunciados na capa - ilustrados e denominados no título, o qual enfatiza a bruxinha, já que o termo vem primeiro, a visualidade altera a proposta e enfatiza o dragão. Capa e título põem em tela que a fantasia comparece no enredo constituído por seres pertencentes ao universo mágico.

Já na capa, o conjunto de elementos icônicos (imagens) e escritos possibilita ao leitor compreender o ambiente onde a história acontece. Se a capa contemplasse apenas o título, perderse-iam sutilezas constituintes do enredo. Nela, o 
emprego da perspectiva aplicada à visualidade da bruxinha, que é moça, aparece em segundo plano, e o dragão (na fase adulta) ocupmna o plano central. A bruxinha, além de estar mais distante do leitor, fica oculta pelo fundo escuro.

A disposição e a presença desses elementos visuais e verbais podem interrogar o leitor. $\mathrm{Na}$ capa, a bruxinha era moça e, no início da narrativa, apresenta-se como criança, visto que na abertura da história a bruxinha é ilustrada como criança. Hipótese: Essa narrativa vai mostrar percurso da vida da personagem? Durante a leitura, poderão surgir outros questionamentos como: $\mathrm{O}$ dragão era diferente desse apresentado com asas de libélula? O que acontecerá? Essas e outras possibilidades podem construir indagações frente à capa para dialogar com o livro. Esses movimentos interrogativos mobilizariam o leitor a construir e a reconstruir a narrativa.

A capa de $A$ bruxinha e o dragão assume função, predominantemente, descritiva ao concretizar, visualmente, os personagens. Outro aspecto notado é a figura colorida do dragão que não solta fogo pelas ventas. No Ocidente, o dragão é interpretado com referência ao medo, tende a ser vilão; no Oriente, o conceito é outro, pois simboliza a sorte. $O$ dragão pai protegia a menina, posição que rompe com dogmas sociais do contexto onde a narrativa estaria sendo lida.

Entre as justificativas para a seleção desta obra nos grupos focais, destacam-se dois posicionamentos. Joãozinho (Grupo 2) menciona gostar da harmonia da capa: "Eu escolhi esse livro porque o título e a capa me interessam, gostei. Tem um dragão na capa, eu gosto". O título com a presença do léxico "dragão" e a ilustração, na capa, trouxeram-lhe reações sobre essa figura mitológica. Essa situação repetiu-se com Gabi (Grupo 1): "Eu escolhi esse porque tem dragão, gosto de monstro. A bruxinha e o dragão acho que é legal". Para tanto, Gabi remete seu gosto a monstros e, por esse motivo, sua preferência por dragões e bruxas buscou identificar no livro suas preferências afetivas e os encontrou nos paratextos.

A quarta capa veicula o press release recuado à esquerda em letras brancas, sobre as ilustrações dos vários dragões apresentados à bruxinha, em fundo preto que se estendem na capa. Esse paratexto foi lido em voz por Joãozinho (Grupo 2), por iniciativa própria antes de apresentar a obra. A escrita mobiliza conhecimentos prévios do interlocutor a buscar outras histórias sobre dragões:

\begin{abstract}
Vários contos de fadas têm dragões entre os personagens, você já deve ter reparado. Em muitas das histórias, eles guardam princesas que estão presas em torres altíssimas e enfrentam príncipes corajosos que pretendem salvar as suas damas e mostrar o tamanho do seu amor. Esses dragões agem como verdadeiros pais, defendendo suas mocinhas e testando seus pretendentes. Na história deste livro, um pai protetor tenta a todo custo atender às vontades da filha, que é muito caprichosa e não vai arredar o pé enquanto não encontrar um dragão de estimação perfeito. Mas, como além de pai ele também é bruxo, a única solução que encontra para tamanho desafio é transformar, ele próprio, em um dragão! E não é que dá certo? A menina, sem saber que aquele ali à sua frente é o pai, logo simpatiza com o dragãozinho... E assim o tempo passa, os dois crescem - sempre juntos e em meio a muita confusão - até que chega o tão temido dia: aquele em que o dragão-mago precisa deixar a sua bruxinha abrir as próprias asas e seguir o seu caminho sozinha. (ALPHEN, 2013, p. 58).
\end{abstract}

A situação temporal em que os fatos acontecem é colocada no press release, que contempla a metamorfose na vida dos protagonistas. O perfil da bruxinha ressalta que o pai fazia as vontades da filha até que chega o momento quando ela precisa voar sozinha. Por meio deste paratexto, o leitor recebe informações relevantes sobre o enredo e poderá sentir-se desafiado a acessar à obra.

São anunciados, neste paratexto, os sentimentos da menina e do pai protetor que não mede esforços para satisfazer a filha. Essas indicações remetem ao interesse pela leitura a partir do que em algumas situações é vivido pela criança na contemporaneidade, seja por meio de 
outras histórias, ou pela presença paternal, que se tem, ou que se gostaria de ter, aspectos esses que constituem a literatura infantil.

Os elementos icônicos e convencionais da capa e da quarta capa antecipam dados da história a ser lida, como por exemplo, as informações do press release que influenciam nas imagens da capa e do título, e vice-versa. Essa proposta de construção dos paratextos demonstra intenções estéticas e discursivas que se complementam antecipando a narrativa.

Entretanto, torna-se necessário atentar para a proposta gráfica da obra, visto que a composição discursiva dos paratextos contém materiais táteis para ser considerada pelo leitor. Diante desses recursos materiais, "nenhum leitor, na verdade, deveria ser indiferente à apropriação das escolhas tipográficas [...] (GENETTE, 2009, p. 36). O livro em questão é composto por 56 páginas, em papel encerado, CouchéReflex Matte , o que constitui espessura mais grossa do que habitualmente se encontra no Brasil e o exemplar requer lombada. Esta veicula de modo centralizado o título da obra, contempla o nome do autor/ ilustrador em tons lilás e verde na parte superior, o que facilita a localização do livro. $\mathrm{Na}$ biblioteca em que este estudo aconteceu, o exemplar estava disposto em pé, com a lombada estreita exposta. Aliás, como o livro literário destinado à criança tende a ser fino, a lombada acaba não favorecendo a localização ou identificação dos exemplares dispostos. Para apresentar o livro lido, Gabi (Grupo 1) exclama: "Olha onde está escondido o nome do cara que escreveu a história!" Exibe a lombada, enquanto soletra o nome do autor. Essas informações parecem despertar-lhe o interesse sobre esse paratexto, diante das conversas mediadas no grupo.

A capa é constituída em papel cartão. A presença de materiais diversificados entre capa e miolo pressupõe que a materialidade da obra assume proposta agradável à sensibilidade do leitor. Nesse sentido, a relação entre o objeto livro também se efetiva por meio de elementos táteis, estéticos e cognitivos presentes no processo de leitura.

$\mathrm{Na}$ penúltima página do exemplar, a nota biográfica sobre o autor Jean-Claude R. Alphen, escrita em terceira pessoa do singular, iniciada pela frase "Era uma vez", traz indícios de uma narrativa a ser contada. E, assim, sucede a história de um menino que adorava desenhar. Começou a trabalhar como caricaturista no Jornal da Tarde, em São Paulo, e ilustrou mais de 50 livros infantis. Recebeu prêmios como o da Revista Crescer, o Glória Pondé, da Fundação Biblioteca Nacional, e o selo Altamente Recomendável, da Fundação Nacional do Livro Infanto Juvenil (FNLIJ). As notas sobre a carreira do autor referenciam que "[...] algumas são obrigatórias. Outras, às vezes as mesmas, são de boa política comercial" (GENETTE, 2009, p. 53), que no caso propiciam conhecimento sobre a produção da obra.

A biografia, por meio de linguagem coloquial, aproxima-se do leitor: "Até que lhe deu na veneta inventar suas próprias histórias" (ALPHEN, 2013, p. 55). Outro elemento constitutivo desta página é a figura de um dragão a voar no canto superior direito. Os interlocutores, ao se deparem com situações em que a autonomia é colocada de modo implícito, sejam nos discursos verbais ou imagéticos, aproximam-se de práticas que incentivam a liberdade.

$\mathrm{Na}$ folha de rosto, há uma ilustração da bruxinha criança, na sacada da torre vendo o dragão colorido voar com asas de libélula. O título do livro, em negrito, grafado em letras minúsculas, situa-se na parte superior da página e o nome do autor acima, grafado em maiúsculas, de modo mais discreto. $\mathrm{Na}$ base da página, encontram-se, ainda, a etiqueta com os dados da escola, o número do registro do exemplar na biblioteca e a data de 
recebimento, paratextos não editoriais; e o selo da editora finaliza a página de rosto (Fig. 2):

Figura 2 - Folha de rosto do livro $A$ bruxinha e o dragão

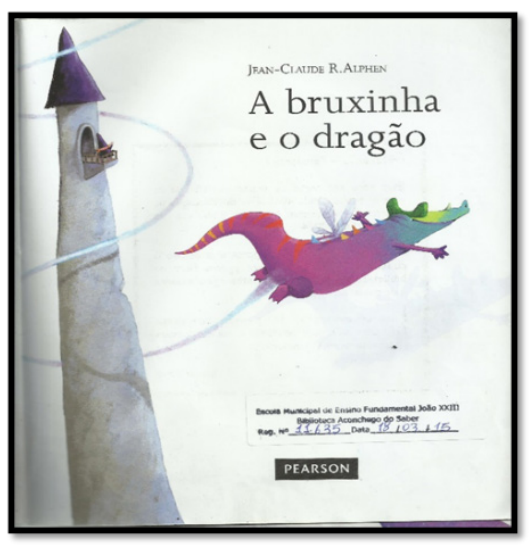

Fonte: Alphen (2013).

$\mathrm{Na}$ folha de rosto, há contraponto com as imagens que compõem a capa. O dragão está crescendo, as marcas de sua passagem, atrás da torre, onde está a bruxinha, demonstram a mobilidade de seu corpo. Já na capa, vimos que o rabo do dragão estava em volta da torre, com um corpanzil. $\mathrm{Na}$ folha de rosto, a bruxinha, na fase infantil, aparece na sacada. Essas nuances temporais expressas pela visualidade inferem sobre conflito, com mensagem implícita ao leitor de que o enredo não será linear, o que pode interferir na leitura atenta, que visa a destacar detalhes da obra para significar o lido.

No verso, constam os dados de catalogação do livro e a ilustração da bruxinha com uma mão na cintura e o dedo apontado para o leitor. A imagem, situada em fundo branco, está em interação direta com o leitor e, nesse sentido, denota-se a posição imperativa da personagem durante a narrativa a ser lida, aspecto que traz indícios sobre a personalidade da protagonista.

Na página seguinte, localiza-se a dedicatória: "Para Julia e Clarice". O paratexto é alinhado à direita, escrito em preto, em fundo branco. Há também, no verso, a imagem da boca aberta do dragão, com três árvores presas em um garfo, prestes a caírem em sua boca, acompanhadas de pássaros voando (Figura 3):

Figura 3 - Dedicatórias do livro A bruxinha e o dragão

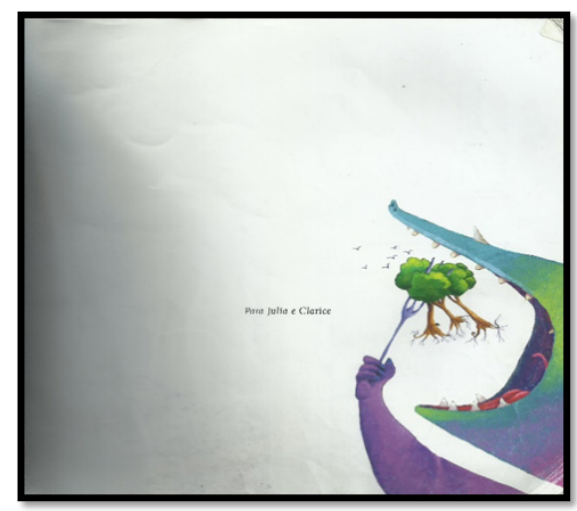

Fonte: Alphen (2013).

As intenções de dedicatória da palavra "para", uma preposição que indica direção, e os respectivos nomes a quem o livro é dedicado interagem diretamente com a imagem em que o dragão está prestes a devorar três árvores. Essa composição deixa implícita a possibilidade de deliciar-se com a obra apresentada.

$\mathrm{Na}$ última página do miolo, a ilustração da bruxinha e o selo da editora FSC estão acompanhados de nota de rodapé. Esta informa sobre a procedência do papel utilizado na edição - provém de florestas gerenciadas de maneira ambientalmente correta. $\mathrm{Na}$ terceira capa, tem-se outra informação: a quantidade de empréstimos do título. Sete crianças matriculadas no quarto ano retiraram o exemplar da biblioteca da Educação Infantil, desde 2015, quando a obra passou a integrar o acervo da escola. 
Figura 4: Ficha de retirada de livro

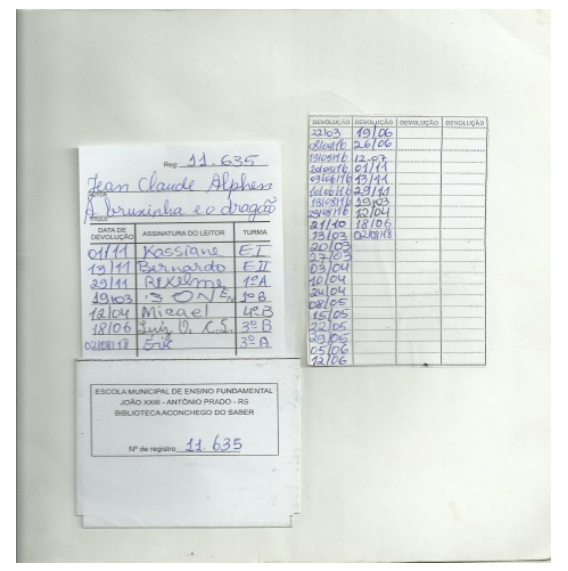

Fonte: Alphen (2013).

$\mathrm{Na}$ capa desta obra, percebe-se que o ilustrador usou elementos da cultura infantil para dar formas a aspectos do enredo como a magia da bruxa e do dragão. Ambos, foram ilustrados com traços que lembram desenhos animados, o que encanta as crianças: “[...] a utilização de um mesmo tipo de desenho cria-se uma onda de consumo que assume fórmulas distintivas similares e na qual também se inclui o livro, de maneira que se pode tornar difícil distinguir a capa de um livro, de um DVD ou de um CD.” (LLUCH, 2006, p. 221).

Nesta perspectiva, a aproximação das crianças em dois grupos focais com esta obra, em meio a outras, pôde ser influenciada pela presença de ilustrações que recriam referências visuais do universo infantil na contemporaneidade.

Paratextos como o press release e a capa trouxeram por meio de texto verbal e ilustração possibilidades para além do livro. O conhecimento prévio do leitor sobre os termos "bruxinha" e "dragão" foram elementos empregados para a escolha desse título. A presença de adjetivos como bruxinha "caprichosa", príncipes "corajosos", pai "protetor" inferem nos sentidos anunciados pelo press, também sugerem pontos de articulação com referenciais que qualificam personagens já conhecidos, criando e recriando possibilidades de leitura.

Além da aproximação do leitor à obra pelos seus conhecimentos prévios, a transitoriedade das fases da vida parece ser um ponto presente na composição de paratextos verbais e visuais. Para além do consumo, abordado por Genette (2009), os elementos paratextuais dessa obra contextualizam o leitor sobre o que será tratado no texto. Os paratextos informam sobre os prêmios do autor e sua posição frente a conquistas profissionais, contextualizando a obra a ser lida, o que alerta sobre a relevância de leitura desses itens pelos mediadores de leitura literária.

A análise dos paratextos pelos estudantes do quarto ano do Ensino Fundamental evidenciou que existe articulação entre os elementos verbais e icônicos na tentativa de apresentar o enredo de modo enigmático. Assim, a leitura atenta dos possíveis desdobramentos dos paratextos na obra, torna-se parte integrante da mediação entre o leitor e o objeto livro, uma vez que se percebe que o enredo é envolvido pela curiosidade apresentada por esses elementos.

O estudo dos paratextos na literatura infantil torna-se relevante na perspectiva da formação de leitores, visto que, “[...] um leitor competente em plena fase formativa pode realizar hipóteses interpretativas sobre o texto literário a partir da informação que estes paratextos lhe facultam." (LLUCH, 2006, p. 218). Assim, quanto mais informações se tem sobre o texto, maiores serão as possibilidades de antecipar dados sobre o título.

A leitura da obra é orientada por determinados paratextos, o que demonstra a interação entre texto, paratexto e o leitor com seu repertório. Nesse sentido, a leitura de um livro apoia-se em outros elementos que vão além do texto, como se observa na figura 5: 
Figura 5 - Transação entre, texto, paratexto, leitor e meio.

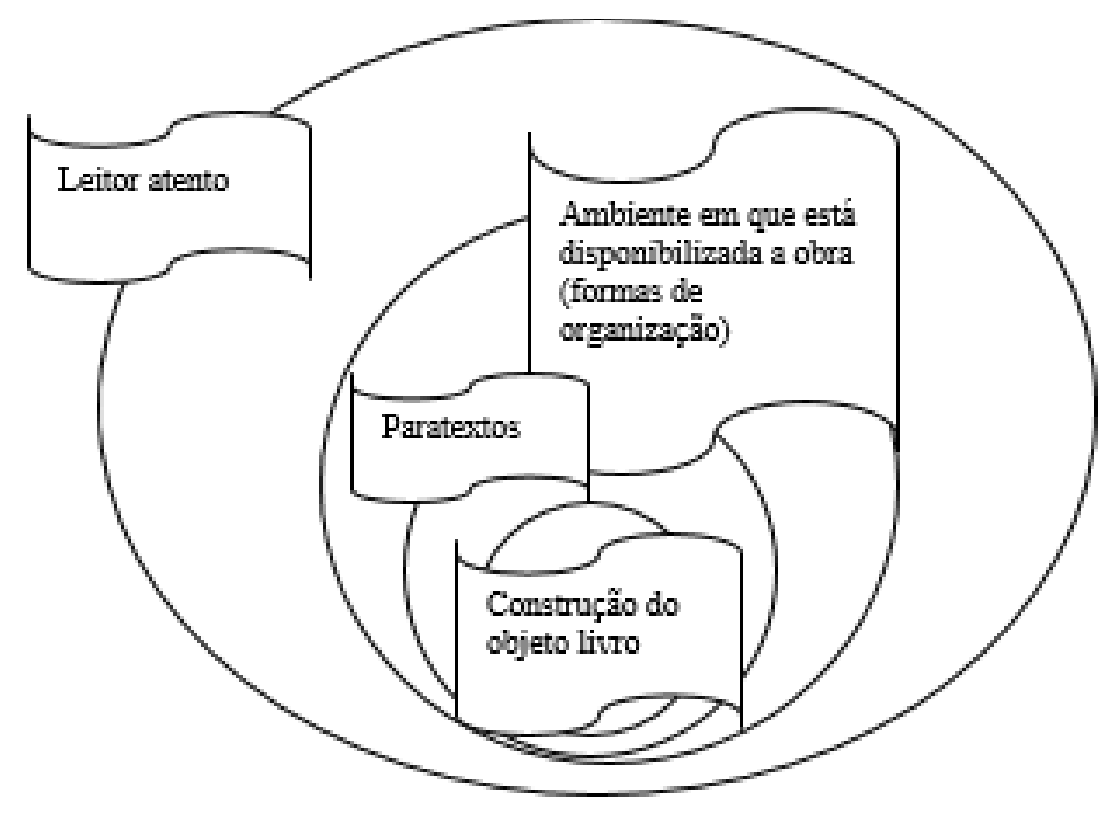

Fonte: Elaborado pelas autoras.

Fonte: Elaborado pelas autoras.

A construção do livro está diretamente ligada à organização dos elementos paratextuais. Texto e paratexto apresentam-se em movimento processual na forma espiral em que sustenta a compreensão da obra, de modo a indicar detalhes que auxiliam a construir sentido perante o lido. Essas relações foram estabelecidas em certo meio, no caso, a biblioteca, que é organizada por concepções de leitura. Os livros estavam dispostos em uma prateleira, organizados na vertical, mas mesmo as obras que têm lombada não se destacam, mesmo a A bruxinha e o dragão, já que a espessura do exemplar não permite a sua identificação pela visualidade. No caso das obras que não têm lombada, caso sejam eleitas aleatoriamente, são os demais paratextos que exercem o papel de transação entre o texto e o leitor. Por fim, para que o leitor compreenda os movimentos entre o texto e os discursos implícitos dos paratextos, ele precisa ser instrumentalizado para atentar a presença desses dados num livro.

\section{CONSIDERAÇÕES FINAIS}

Os paratextos do livro analisado neste estudo trazem elementos icônicos e verbais na tentativa de dialogar com os possíveis leitores e mediadores de leitura. Nessa perspectiva, os elementos paratextuais são compostos de discursos articulados na tentativa de sensibilizar o leitor, ao mesmo tempo, utilizam recursos próprios da cultura infantil, para aproximar o objeto livro do seu público. O apelo, por exemplo, a figura da bruxa, já presente no imaginário e na cultura infantil, é um dado a ser destacado na composição do título.

Logo, na capa, A bruxinha e o dragão apresenta a possibilidade de o possível leitor identificar-se com elementos constituintes do universo posto. A forma como as ilustrações são colocadas chamam a atenção dos estudantes que selecionam o exemplar. O título indica personagens caros às crianças dragões e bruxas -, e a narrativa atualiza tema fundamental para o leitor.

A organização dos elementos paratextuais, diante do enredo, pode intervir na leitura, com indícios sobre a história. Ou seja, a leitura dos paratextos pode atuar como pistas a serem seguidas ou abandonas pelo interlocutor na interação com a obra. O press release, por exemplo, auxiliou um 
dos estudantes a falar sobre a obra aos demais participantes, sendo que ele leu este paratexto, antes de apresentar a narrativa.

Em termos de mediação de leitura por um adulto, as notas com a referência a prêmios e a outros selos presentes na capa ou na folha de rosto podem mobilizar o mediador para o acesso ao livro. Nesse sentido, a nota do PNBE no início de cada exemplar recebido pela escola, o selo relacionado a idade a que a obra se destina e o selo de venda proibida orientam não só a criança, mas os mediadores de leitura literária. Para tanto, os paratextos estabelecem relações para além do público ao qual é dedicado, o infantil, e atingem o adulto. Eles também se relacionam ao espaço em que atuará a obra e a sua dimensão cultural no meio em que passa a circular.

A nota biográfica apresenta o autor e traz informações relevantes na mediação de leitura, uma vez que autores e ilustradores são integrantes de um circuito de produção. Esses dados são relevantes à escola que recebe livros de um governamental e assume olhar atento e sensível para a proposta de mediação da leitura literária.

Em síntese, este estudo evidenciou que a atenção aos paratextos presentes em livros literários, integrantes de uma política pública, apoiaria os mediadores de leitura na organização e apresentação das obras literárias infantis, visto que, no espaço observado, as capas, ficavam escondidas em prateleiras, e os livros estavam organizados por faixa etária, o que dificulta o acesso dos estudantes aos exemplares. Assim, almeja-se contribuir para a análise dos elementos paratextuais na perspectiva da formação de leitores literários na escola.

\section{REFERÊNCIAS}

ALPHEN, Jean-Claude R. A bruxinha e o dragão. São Paulo: Pearson Education do Brasil. SP, 2013.
BRASIL. Ministério da Educação. Secretaria de Educação Fundamental. PNBE na escola: Literatura fora da caixa. Brasília: MEC, 2014. Disponível em: http://portal. mec.gov.br/index.php?option $=\mathrm{com}_{-}$ content\&view $=$ article\&id $=20407$ \&Itemid $=1134$. Acesso em: 28 jun. 2019.

BRASIL. Programa Nacional da Biblioteca Escolar (PNBE). Ministério da Educação. Disponível em: http://portal. mec.gov.br/index.php?option $=c_{\text {com }}$ content\&vi e w $=$ article \&id $=12548$ : saibamais \&catid $=309$ :programa-nacionalbiblioteca-da-escola\&Itemid=574. Acesso em: 09 nov. 2018.

BRASIL. Edital de convocação 04/2012. https://www.fnde.gov.br/index.php/centraisde-conteudos/publicacoes/category/109editais?download=7721: edital-pnbe-2014. Acesso em: 20 abr. 2020.

CANDIDO, Antonio. O direito à literatura. São Paulo: Duas Cidades, 1995.

GENETTE, Gérard. Paratextos editoriais. Tradução Álvaro Faleiros. Cotia, São Paulo: Ateliê Editorial, 2009.

LLUCH, Gemma. Para a seleção adequada do livro: das capas ao estilo da literatura comercial. In.: AZEVEDO, Fernando (coord.). Língua materna e literatura infantil: elementos nucleares para professores do ensino básico. Lisboa: Lidel, 2006.

MOTA, Rildo José Cosson. Avaliação pedagógica de obras literárias. Educação, Porto Alegre, v. 35, n. 3, p. 308-318, set./dez. 2012.

NIKOLAJEVA, Maria; SCOTT, Carole. Livro ilustrado: palavras e imagens. Tradução Cid Knipel. Imprenta. São Paulo: Cosac Naify, 2011.

RAMOS, Flávia Brocchetto. Literatura infantil: de ponto a ponto. Curitiba: CRV, 2010.

RAMOS, Flávia Brocchetto. Literatura na escola: da concepção à mediação. Caxias do Sul: EDUCS, 2013. 
RAMOS, Flávia B.; NEVES, Nathalie V. A divulgação do acervo do PNBE 2008 em escolas municipais de Caxias do Sul. Signo (UNISC. Impresso), v. 34, p. 107-119, 2009.

Submissão: junho de 2020.

Aceite: março de 2021. 